\title{
Systematic experimental investigation of filtration losses of drilling fluids containing silicon oxide nanoparticles
}

\author{
A.V. Minakov",a,*, E.I. Mikhienkova ${ }^{a}$, Y.O. Voronenkova ${ }^{a}$, A.L. Neverova ,G.M. \\ Zeer $^{\mathrm{a}}$, S.M. Zharkov ${ }^{\mathrm{a}, \mathrm{c}}$ \\ ${ }^{a}$ Siberian Federal University, 79 Svobodny Prospect, Krasnoyarsk 660041, Russia \\ ${ }^{b}$ Kutateladze Institute of Thermophysics, SB RAS, 1 Academica Lavrentyeva Prospect, Novosibirsk 630090, Russia \\ ${ }^{c}$ Kirensky Institute of Physics, Federal Research Center KSC Siberian Branch Russian Academy of Sciences, 50/38 \\ Academgorodok, Krasnoyarsk 660036, Russia
}

\begin{abstract}
This paper presents the results of silicon oxide nanoparticles-incorporated drilling fluid filtration through a porous medium with different permeability. A water-based clay suspension was used as a basic model for creating investigated fluid samples. AlN (aluminium nitride) particles were used as a dispersed phase. The concentration of microparticles varied from 0.5 to $4.00 \mathrm{wt} \%$, while the microparticles size varied from 1 to $10 \mu \mathrm{m}$. The concentration of $\mathrm{SiO}_{2}$ nanoparticles was changed within the range of 0.25 and $4.00 \mathrm{wt} \%$, while the nanoparticles size varied from 5 to $100 \mathrm{~nm}$. It was shown that filtration of drilling fluids with nanoparticles inclusions depends on their concentration, size and material, the concentration and size of microparticles and the pore sizes of ceramic filters. The addition of the nanoparticles leads to a significant reduction in filtration of a microsuspension and affects the structure and thickness of a cake formed on the surface of a filter. The main novelty of this work lies in the fact that the effect of the addition of nanoparticles on filtration losses depends on the ratio between nano and microparticles. It was shown that the positive effect of nanoparticle additives on filtration losses is determined not only by the properties of nanoparticles (size and concentration), but also by the properties of microparticles contained in the drilling fluid, as well as the characteristics of the rock (pore size).
\end{abstract}

Keywords: drilling fluid, nanoparticles, microsuspension, filtration loss, permeability, porous medium, ceramic filter.

\section{Introduction}

One of the important characteristics of a drilling fluid is filterability. Drilling mud could filter through borehole walls during drilling for oil and gas. This process is called 'filtration losses', and causes an increase in the well construction cost. Moreover, drilling fluid filtration

* Corresponding author.

E-mail addresses: AMinakov@sfu-kras.ru (Andrey Minakov) 
loss is one of the main reasons of cracks formation and borehole instability. That is why different methods apply to borehole walls hardening. Various dispersive $(1 \div 100 \mu \mathrm{m})$ materials are usually used as filling agents, which can penetrate into formation and seal it. However, microparticles usage appeared to be ineffective in low permeable reservoirs, where a porous size is no more than $0.1-1 \mu \mathrm{m}$. In that regard there have been several investigations, where nanoparticles' suspensions are used as filtrate agents (Evdokimov, 2016; Mijić et al., 2017; Riveland 2013).

Ismail et al. (2014a) studied the water-based drilling fluid containing nanoparticles of metal oxides as additives. The results show that $2 \mathrm{wt} \%$ nanoparticles in a drilling fluid leads to a decrease in filtrate losses by $22 \%$ for the $\mathrm{Al}_{2} \mathrm{O}_{3}$ nanoparticles and by $38 \%$ - for the $\mathrm{TiO}_{2}$ ones. Vryzas et al. (2015) examinatied the water-based drilling fluids with $\mathrm{Fe}_{2} \mathrm{O}_{3}$ and $\mathrm{SiO}_{2}$ nanoparticles. Experimental data showed a considerable decrease in filtration loss of fluids containing the $\mathrm{Fe}_{2} \mathrm{O}_{3}$ nanoparticles in LTLP and HTHP conditions. Filtration effectiveness was undermined with the increase of the $\mathrm{Fe}_{2} \mathrm{O}_{3}$ nanoparticles concentration. As a result it has been found that $0.5 \mathrm{wt} \%$ is an adequate concentration of $\mathrm{Fe}_{2} \mathrm{O}_{3}$, above which nanoparticles create new layers on filter cake surface and negatively affect fluid loss and filtration characteristics. A sample with the $\mathrm{Fe}_{2} \mathrm{O}_{3}$ nanoparticles of $0.5 \mathrm{wt} \%$ exhibited the improved results of filtration loss, which decreased from $10.9 \mathrm{~cm}^{3}$ to $9.6 \mathrm{~cm}^{3}$ (that was $12 \%$ lower than for a basic fluid). As for the samples with the $\mathrm{Fe}_{2} \mathrm{O}_{3}$ nanoparticles of 1.5 and $2.5 \mathrm{wt} \%$, filtration losses amounted to 9.0 and $8.8 \mathrm{~cm}^{3}$ (this is a 17.4 and $19.3 \%$ decrease comparatively to a basic fluid filtration loss). Samples containing silicon oxide nanoparticles in its turn have negative influence on fluid loss characteristics. Drilling fluid filtration increases to $57.8 \%$ relative to a basic fluid if for example, $2.5 \%$ of nanosized silicon oxide had been added. Salih et al. (2016) investigated the water-based fluid with different concentrations of colloidal silicon dioxide nanoparticles at the size of $5.7 \mathrm{~nm}$. Filtration characteristics were improved by adding nanoparticles at a concentration level of 0.7 $\mathrm{wt} \%$ according to results. The optimal concentration of nanoparticles is $0.1 \div 0.3 \mathrm{wt} \%$. Increasing the concentration of $\mathrm{SiO}_{2}$ nanoparticles gradually reduced the filtration losses. The most 
significant enhancement of filtration properties is observed after adding 0.1 wt $\%$ of nanoparticles, but further concentration rise causes the reduction of filtration properties.

Ragab and Noah (2014) described the research of the $\mathrm{SiO}_{2}$ nanoparticles influence on filtration, where it's been evaluated that using particles in the range of $5 \div 15 \mathrm{~nm}$ in size provides two times the decrease in filtration losses. At the same time, coarse nanoparticles $(70 \div 90 \mathrm{~nm})$ reduce it by $20 \%$. Dhiman (2016) also discussed the effect of the nanoparticles size on this parameter according to which $\mathrm{Fe}_{2} \mathrm{O}_{3}$ nanoparticles of $3 \mathrm{~nm}$ size appeared to decrease clay drilling fluid filtration better than ones of $30 \mathrm{~nm}$ size. Akhtarmanesh et al. (2013) examined water-based drilling fluids containing colloidal silica nanoparticles as additives. It was observed that adding nanoparticles to a salt-loaded drilling fluid decreases the filtration losses by $68 \%$ and permeability by $97 \%$. The minimum of nanoparticles content is $10 \mathrm{wt} \%$ and it is necessary for reducing permeability and fluid losses. Filtration properties for $35 \mathrm{~nm}$ sized particles appeared to be better than for $50 \mathrm{~nm}$ sized ones.

Moreover penetration of water-based drilling mud with addition of the $\mathrm{SiO}_{2}$ nanoparticles of the $20 \mathrm{~nm}$ size in shale was studied (Mukul et al., 2012). The results provide evidence for that nanoparticles incorporation gives the decrease in filter losses in 10-100 times. Hoelscher et al. (2012) examined the application of water-based drilling fluids with nanoparticles inclusions in order to minimize shale permeability. An addition of nanoparticles leads to reduction in sample permeability from initial $0.153 \mathrm{nD}$ to $0.0042 \mathrm{nD}$ by $98 \%$, which is followed by a decrease in filtration loss. The effect of using multiwall carbon nanotubes and nanosized metal oxides (titanium, aluminium and copper oxides) on water-based drilling fluid characteristics was considered (Ismail et al., 2014b). Experimental data show a diminution of filtration loss by $65 \%$ and of filter cake thickness by $30 \%$ after $1 \mathrm{~g}$ addition of carbon nanotubes. The presence of titanium oxides in a water-based drilling fluid has helped to reduce fluid losses more than by $50 \%$ and cake thickness by $30 \%$. Water-based bentonite suspensions (deionized water and $7 \mathrm{wt} \%$ of bentonite) with incorporation of iron oxides $\left(\mathrm{Fe}_{3} \mathrm{O}_{4}\right)$ at concentration of $0.5 \mathrm{wt} \%$ and at size of 
7-50 nm were investigated (Vryzas et al., 2016). The results of LPLT filtration with the use of 7$8 \mathrm{~nm}$ sized particles show the reduce of final filtrate volume by $25.7 \%$ and filter cake thickness by $5.5 \%$ in comparison with a basic liquid. Filtration behavior in HTHP conditions exhibits higher fluid loss decrease: fluid loss amount is $34.3 \%$ for smaller nanoparticles and $40 \%$ for nanoparticles at size of $50 \mathrm{~nm}$ in contrast to the basic liquid. Filtration cakes have increased in thickness for fluids with nanoparticles of 7 and $50 \mathrm{~nm}$ sizes by 10 and $9 \mathrm{~mm}$ respectively compared to $7 \mathrm{~mm}$ thickness after filtering the basic drilling mud. Mahmoud et al. (2016) represented a basic drilling fluid as a liquid with bentonite concentration of $7 \mathrm{wt} \%$ in deionized water and with presence of ferrum and silicon nanoparticles. The use of iron oxide nanoparticles has made the substantial filtrate volume decrease ( $43 \%$ for $0.5 \mathrm{wt} \%$ ) possible with insignificant augment in filter thickness by $17.32 \%$ in compare with basic liquid. However, the addition of $\mathrm{SiO}_{2}$ nanoparticles leads to filtrate volume and cake thickness increase. Nanoparticles concentration growth in its turn resulted in boosting fluid losses and cake thickness for both types of particles. Water-based drilling fluids containing silicon oxide nanoparticles at the size of 10-20 nm were considered (Kang et al., 2016). In accordance with the results nanoparticles lead to filtration reduction and the higher their concentration is, the stronger the effect is. For example, filtration losses have decreased by $42.8 \%$ with presence of nanoparticles at amount of 5 wt $\%$ and by $68.0 \%$ with $10 \mathrm{wt} \%$ of nanoparticles.

There are several studies where the absence of dependence between nanoparticles additions and filter losses is exhibited. Li et al. (2015b) represented study of a water-based drilling fluid containing bentonite, polianionic cellulose and cellulose nanocrystals. Adding cellulose microparticles effected significantly filtration loss reduction as it led to low permeable filtration cakes creation. Experimental results did not show any dependences between the nanoparticle concentration and filtration characteristics. In a study (Taraghikhah et al., 2015) two water-based drilling fluid samples with nanosized $\mathrm{SiO}_{2}$ addings at concentration of $0.5,1$ and 2 
wt\% was made. Nanoparticles don't diminish fluid loss volume. Moreover, filtration loss tends to rise with higher concentrations $(>1 \mathrm{wt} \%)$.

Meanwhile there are studies describing filtration loss increase of drilling fluids after nanoparticles incorporation. For example, Riveland (2013) exhibited that losses after 30 minutes filtration increase by $23 \%$ after adding $1 \mathrm{wt} \%$ of $\mathrm{SiO}_{2}$ nanoparticles at the size of $100 \mathrm{~nm}$ and by $47 \%$ after adding $1 \mathrm{wt} \%$ of $7 \mathrm{~nm}$ sized particles. The properties of bentonite drilling fluids including iron oxide nanoparticles were studied (Jung et al., 2011). As experimental results show there is no dependence between the nanoparticle concentration and size and filtration characteristics. Only 0.5 wt $\%$ bentonite drilling fluid with $30 \mathrm{~nm}$ sized $\mathrm{Fe}_{2} \mathrm{O}_{3}$ adding showed a decrease in the filtration loss amount compared to $5.0 \mathrm{wt} \%$ concentrated bentonite fluid. As the $\mathrm{Fe}_{2} \mathrm{O}_{3}(30 \mathrm{~nm}$ sized) concentration increases from $0.5 \mathrm{wt} \%$ to $5.0 \mathrm{wt} \%$ in bentonite drilling fluid, the filtrate volume increases by $18.0 \%, 17.9 \%$ and $25.2 \%$ in average in 30,60 and 90 minutes respectively.

Therefore all analyzed data show that there are so many unanswered questions for the drilling fluid filtration field. In particular, there are no studies on the joint effect of nano and microparticles on the filtration properties of drilling fluids. In addition, the effect of pore size of the core on the filtration capacity of drilling fluids with additives of micro and nanoparticles remained unexplored. Our work is devoted to the answers to these questions. This demands further systematic experimental investigations, which this work is devoted to. A maximum possible number of factors, which influence the filtration of a drilling fluid with nanoparticles, was tried to be studied in contrast to other works.

\section{Experiment methodology}

A water-based clay suspension was used as a basic model of drilling fluid. Clay as a gelling agent is a typical component of the majority of drilling fluids due to its cheapness and high operating characteristics. Montmorelian clay powder of Tagansky deposit was used at the concentration of $5 \%$ in this work. Powder of chemically inert aluminium nitride AlN produced 
by OOO 'PLATINA' was used as bridging agent of drilling fluid and the average microparticles size varied from 1 to $10 \mu \mathrm{m}$. A drilling mud sample was made with adding particles into distilled water and intensive mingling during 30 minutes with the use of high-speed mixer at 20000 RPM. The essential aspect of clay suspension establishment was final clay swelling lasting for two days after mixing all the components. Suspension colloidal stability was controlled by analyser TURBISCAN LAB. Then the necessary amount of previously produced nanosuspensions was inserted into the clay suspension. The same amount of distilled water was poured into the sample of a basic clay suspension to achieve equal weight concentration in all the investigated fluid samples. The standard two-stage approach was used for producing nanosuspension as demonstrated (Rudyak et al., 2016, 2017). It consists of the following procedure: required amount of powder was added to a liquid to produce the suspension. In order to destroy nanoparticles aggregations the suspension is subjected to ultrasonication with the use of apparatus "Volna" UZTA-0.4/22-OM.

Particles of silicon oxide were used as nanoparticles and their concentration varied from 0.25 to $4 \mathrm{wt} \%$ and size - from 5 to $100 \mathrm{~nm}$. Combined acoustic and electroacoustic spectrometer DT-1200 was used for determination of the nanoparticles size. It is designed for complex investigations of water-based suspensions and emulsions containing nano- and microparticles and is made as the most powerful equipment for studying optically opaque concentrated dispersed systems of no more than 50 volume $\%$.

The value of main parameters of considered drilling fluids is presented in Table 1 .

The scanning electron microscopy (SEM) of JSM-7001F (JEOL, Japan) equipped with the energy dispersive spectrometer Oxford Inca Energy 350 was used for particles size and elemental control.

Typical view of clay drilling fluid particles is shown on Fig. 1. These are images of dried filter cakes taken after drilling fluid filtration. SEM data show that a filter cake is made of clay flakes, if there were no nanoparticles (Fig.1). Elemental clay composition is presented in Tab. 2. 
Table 1. Variable parameters for the study of drilling fluid.

\begin{tabular}{|c|c|c|c|c|c|c|c|}
\hline parameter* & measurement unit & \multicolumn{6}{|c|}{ value } \\
\hline$\varphi$ clay & \multirow{3}{*}{ wt $\%$} & \multicolumn{6}{|c|}{5} \\
\hline$\varphi$ nanoparticles & & 0 & 0.25 & 0.5 & 1 & 2 & 4 \\
\hline$\varphi$ microparticles & & 0 & 0. & & & 2 & 4 \\
\hline$d$ nanoparticles & $\mathrm{nm}$ & 5 & 10 & 25 & 40 & 50 & 100 \\
\hline$d$ microparticles & \multirow{3}{*}{$\mu \mathrm{m}$} & 1.2 & \multicolumn{2}{|r|}{2} & \multicolumn{2}{|c|}{3.5} & 10 \\
\hline$D$ by air & & 3 & 5 & & & 20 & 35 \\
\hline$D$ by mercury & & 10 & 12 & & & 40 & 50 \\
\hline
\end{tabular}

$* \varphi$-concentration; $d$-particle diameter; $D$-core pores diameter

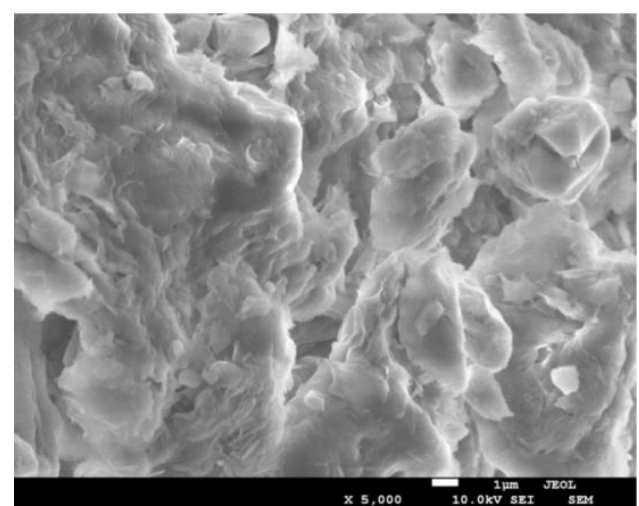

a)

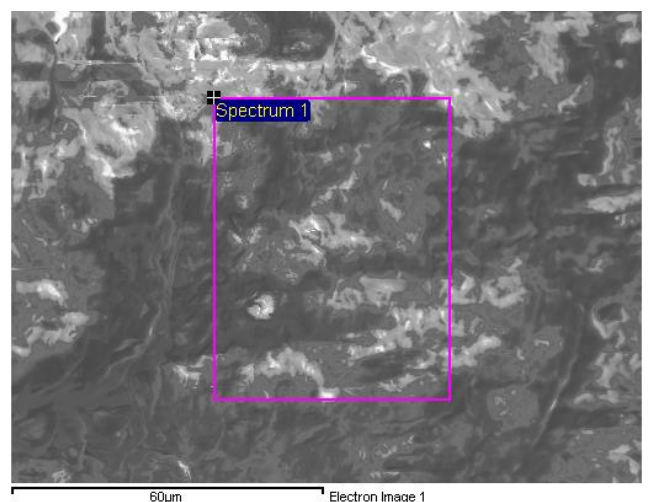

b)

Fig. 1. SEM micrograph of clay particles: in secondary electrons (a), with spectrum marker (b).

Table 2. Clay, elemental composition of the sample

\begin{tabular}{l|c|c|c|c|c|c|c|c}
\hline \multicolumn{1}{l}{ Bentonite, atomic composition. \% } \\
\hline Element & $\mathrm{O}$ & $\mathrm{Na}$ & $\mathrm{Mg}$ & $\mathrm{Al}$ & $\mathrm{Si}$ & $\mathrm{Ca}$ & $\mathrm{Mn}$ & $\mathrm{Fe}$ \\
Content & 63.39 & 0.81 & 1.74 & 6.22 & 22.01 & 0.48 & 2.27 & 3.08 \\
\hline
\end{tabular}

Filtration of studied suspensions was examined with the use of imitating rock ceramic filters of OFITE company. A filter is represented as cylindrical disk made from compressed sand rock with the diameter of $63.5 \mathrm{~mm}$ and height of $6.4 \mathrm{~mm}$. An average porous size varied within the range of 3 and $35 \mu \mathrm{m}$ (defined by air) or 10 and $50 \mu \mathrm{m}$ (defined by mercury). Such porous sizes correspond to permeability change of filter's porous medium from 1.35 to 14.97 Darcy. Filter permeability was determined with the use of probe permeameter PLAB 200. Filter press OFITE HPHT 171-01 made for borehole conditions modeling was used for filtration examination of microsuspensions (Fig. 2a,b).The experiment was performed as follows: $400 \mathrm{ml}$ of examined suspension was poured into filter press, then it filtered through relevant ceramic disk under the pressure of 100 psi. Filtrate volume, which is also called filtration loss, was 
measured after 30 minutes of experiment. Each experiment was repeated three times and data spread is no more than $5 \%$.

The viscosity investigation of drilling fluids modified by nanoparticles was performed by OFITE HPHT viscometer. The results of the experiment is shown in the work (Minakov et al. 2018a, 2018b). Obtained data exhibited that adding nanoparticles to drilling fluids could significantly change their effective viscosity even at extremely low concentrations. It was shown that the majority of considered examples led to an increase in effective viscosity. The viscosity appeared to be dependent on the size of added particles: the smaller nanoparticles were, the higher effective viscosity was. All studies of drilling fluids were carried out at room temperature.

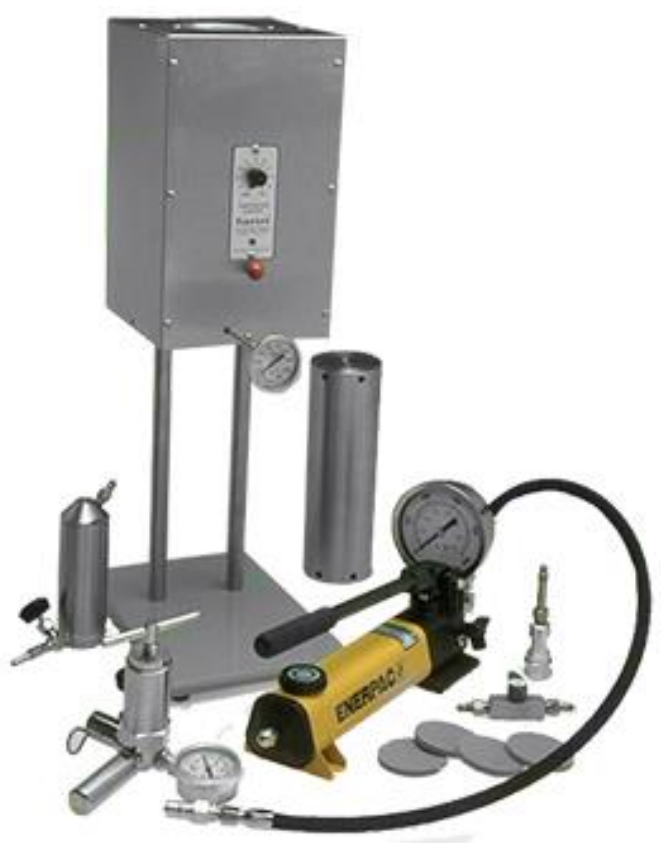

a)

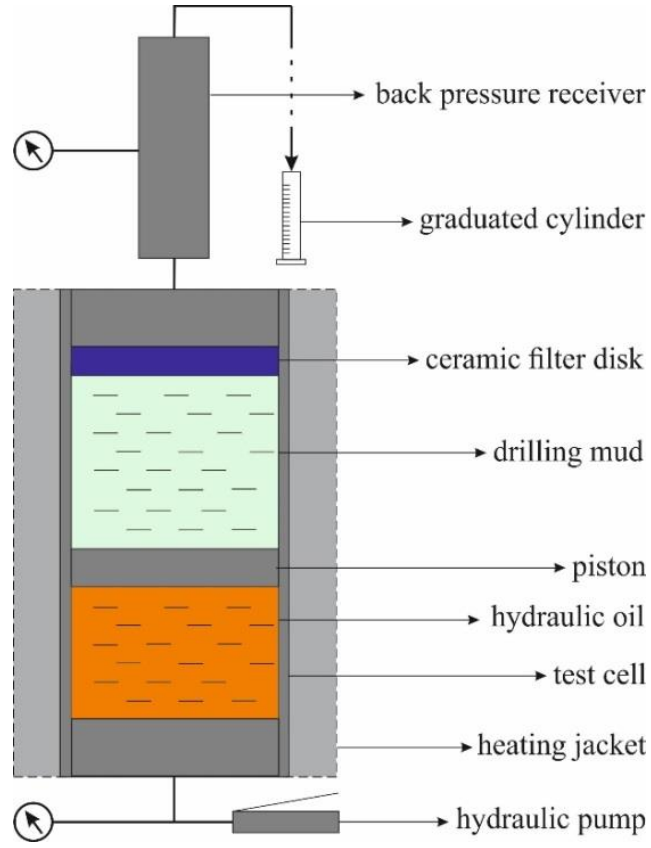

b)

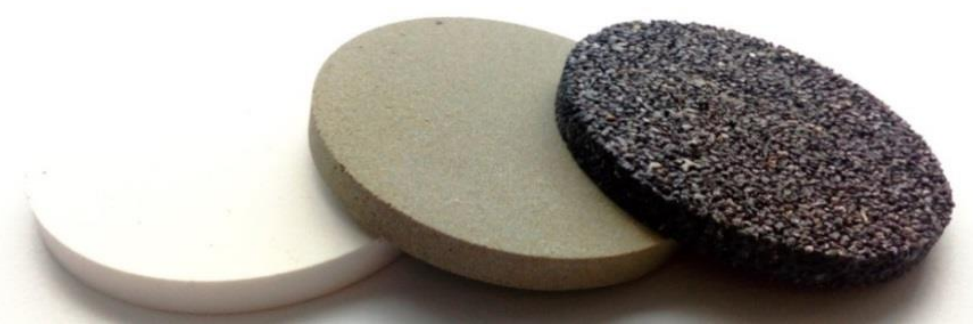

c)

Fig.2. Filter press OFITE HPHT 171-01 (a); installation diagram (b); ceramic filters, imitating rock (c).

\section{Results and discussion}

\subsection{The effect of nanoparticle concentration}


The effect of nanoparticle concentration on the filtration properties of drilling fluids was investigated. The dependence of the fluid volume filtered through a ceramic filter with a pore size of $20 \mu \mathrm{m}$ (by air) and containing added AlN microparticles $1 \mu \mathrm{m}$ in size on the concentration of silicon oxide nanoparticles with an average particle size of $5 \mathrm{~nm}$ is shown in Fig. 3.

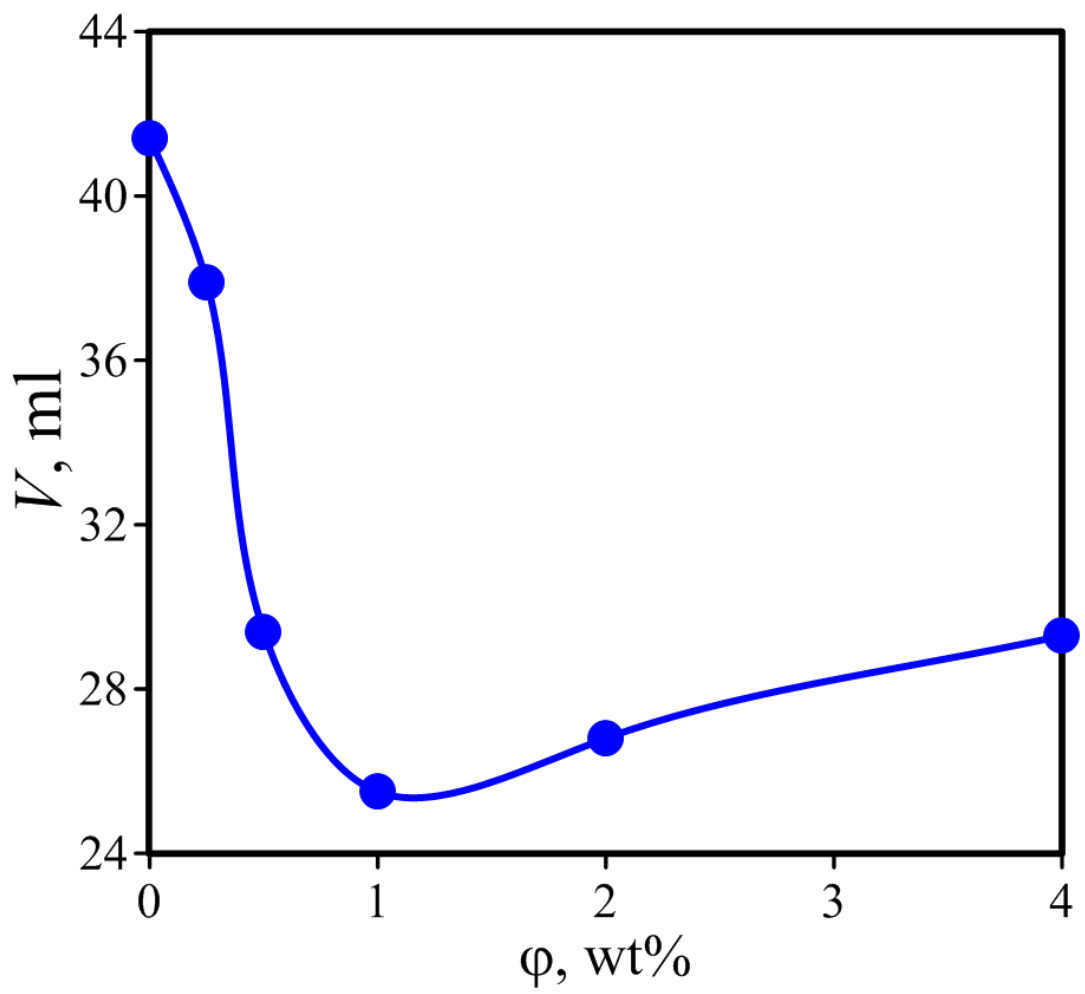

Fig. 3. Filtration loss depending on the $\mathrm{SiO}_{2}$ nanoparticle concentration.

As can be seen, the addition of nanoparticles to the drilling fluid significantly affects the filtration loss value. Besides, the dependence on the concentration is non-monotonic in nature. The maximum reduction of filtrate loss was observed at the concentration of $1 \mathrm{wt} \%$ which resulted in a decrease from $42 \mathrm{ml}$ to $25 \mathrm{ml}$ ( $40 \%$ decrease from original value). A further increase in the concentration of nanoparticles is inexpedient, since it leads to an increase in filtration loss, although quite insignificant. It should be noted that the addition of nanoparticles affects the structure and thickness of the cake formed on the filter surface. As for a solution without nanoparticles incorporation, no cake as such is formed. A loose clay mass of one $\mathrm{cm}$ thick, remains on the filter surface. The addition of nanoparticles leads to the formation of a rather dense and homogeneous cake with a thickness of 2-3 $\mathrm{mm}$. The thickness of this cake is 
reduced slightly with the increasing of nanoparticles concentration as demonstrated (Minakov et al. 2018b, 2018c).

Contreras et al. (2014) explained the physical mechanism of filtration loss reduction after adding nanoparticles to drilling fluid. In case of nanoparticles absence an easily permeable filter cake is formed on the filter surface from microscopic particles of a standard filtrate reducer and clay particles. The addition of nanoparticles leads to the fact that they fill the pores in the filtration cake and make it more compact and poorly permeable.

Qualitatively, all the results obtained in our work confirm this hypothesis. We used electron microscopy to prove this hypothesis. Studies of the microstructure and phase composition of cakes after filtration were carried out with a scanning electron microscope (SEM) JSM-7001F (JEOL, Japan) equipped with an energy dispersive spectrometer Oxford Inca Energy 350. The SEM data show that the cake on the filter surface is formed by clay flakes in the absence of nanoparticles (Fig. 1). The incorporation of microparticles, which are inevitably present in any drilling fluid, makes this cake loose. Microparticles are placed between the clay flakes, making the cake more permeable (see images in Fig. 4 on the left). The addition of nanoparticles to the clay solution, both with and without microparticles, causes them to fill in the pores between the clay flakes and microparticles, thereby reducing the permeability of the cake on the filter surface (see images in Figs. 4 and 6 on the right). A 5000-times magnification shows that the nanoparticles form clusters which cover the pores between the clay particles and the AlN microparticles. 

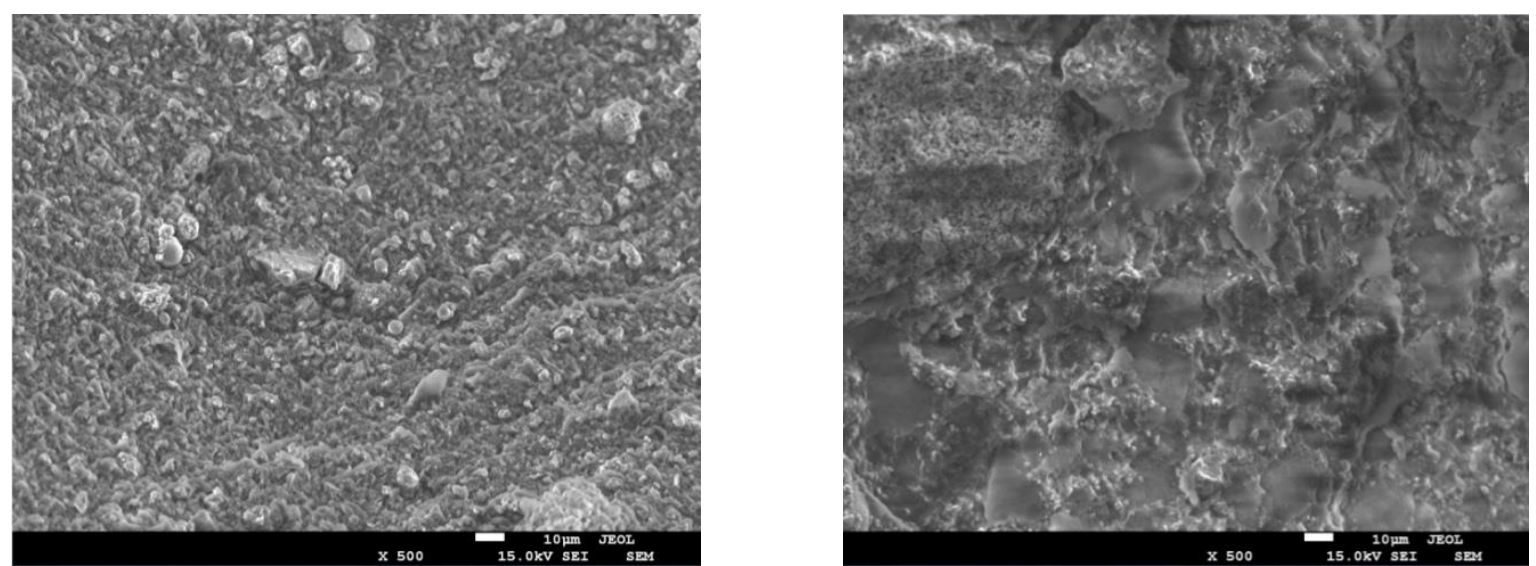

a) Magnification by 500 times
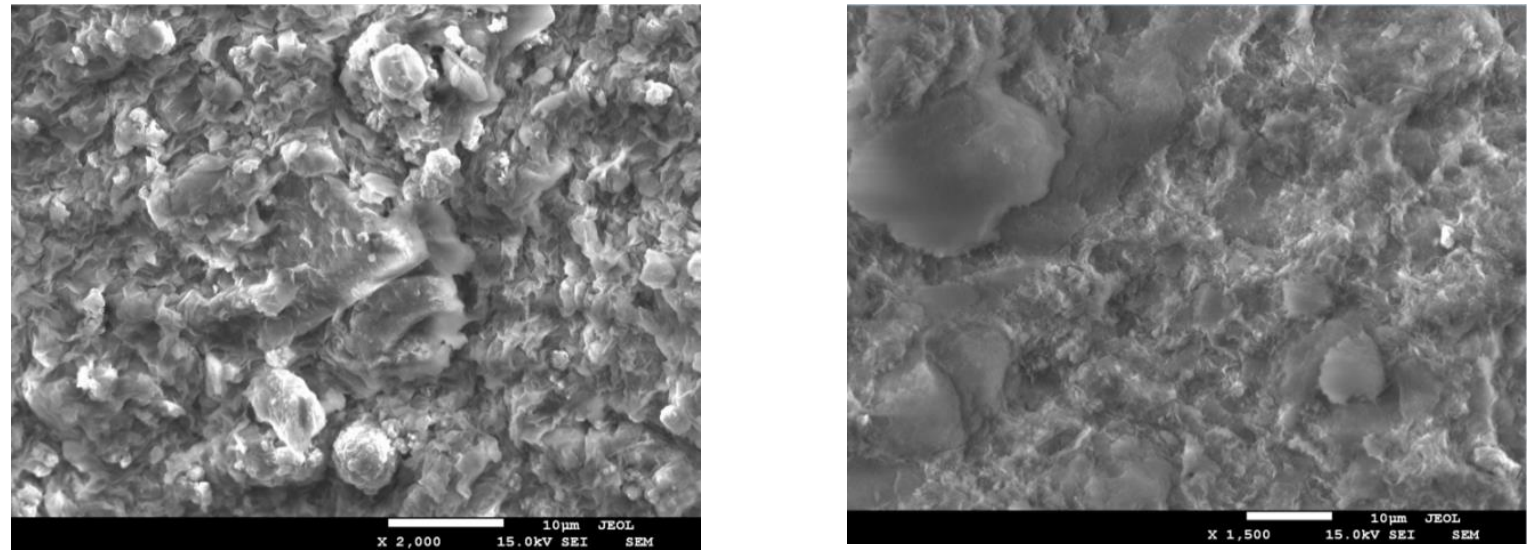

b) Magnification by $1500-2000$ times
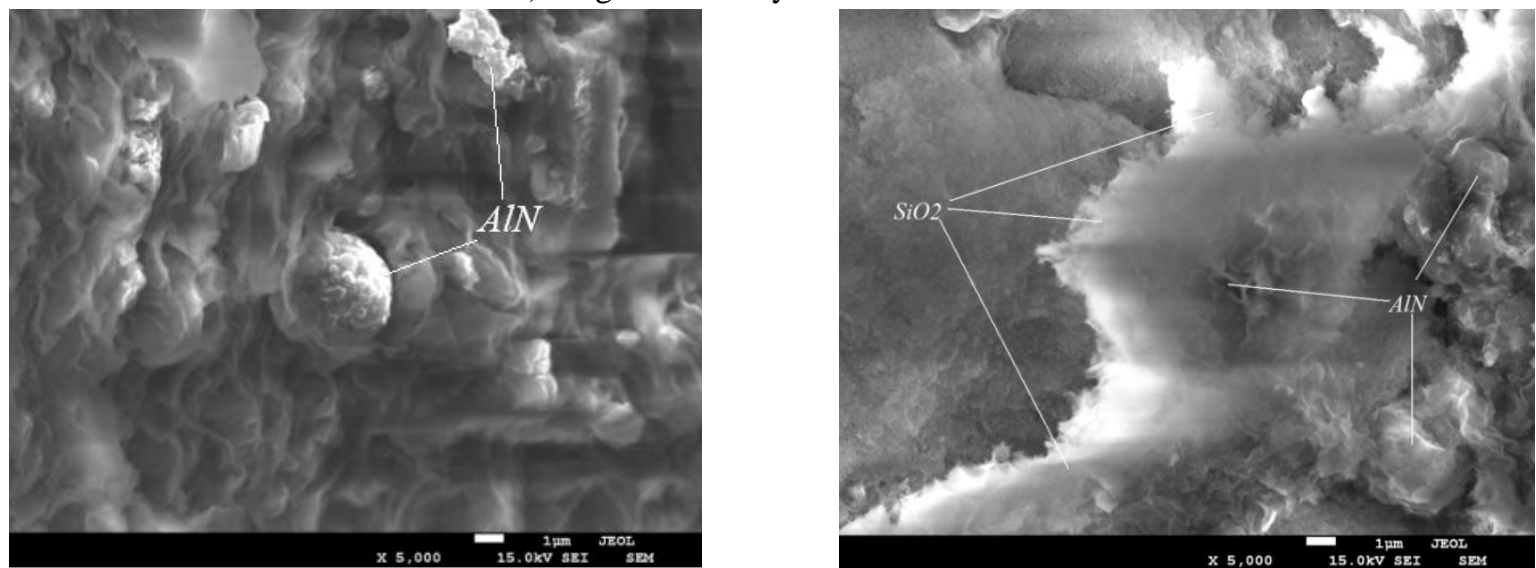

c) Magnification by 5000 times

Fig. 4. The SEM images of the filter cake of the drilling fluid containing $2 \%$ of AlN microparticles $1 \mu \mathrm{m}$ in size without the addition of nanoparticles (left images), and with the addition of $\mathrm{SiO}_{2}$ nanoparticles (right images).

The effect of filling in the space between the clay flakes with nanoparticles is clearly seen in the series of Fig. 5 at high magnification of 50000 times. The images of the individual $\mathrm{SiO}_{2}$ nanoparticles, which are located between the clay particles, can be seen. Thus, it was proved by means of scanning electron microscopy, that the main reason for reducing filtration loss after adding nanoparticles to clay solutions is the filling in the pores of the filter cake with nanoparticles. 


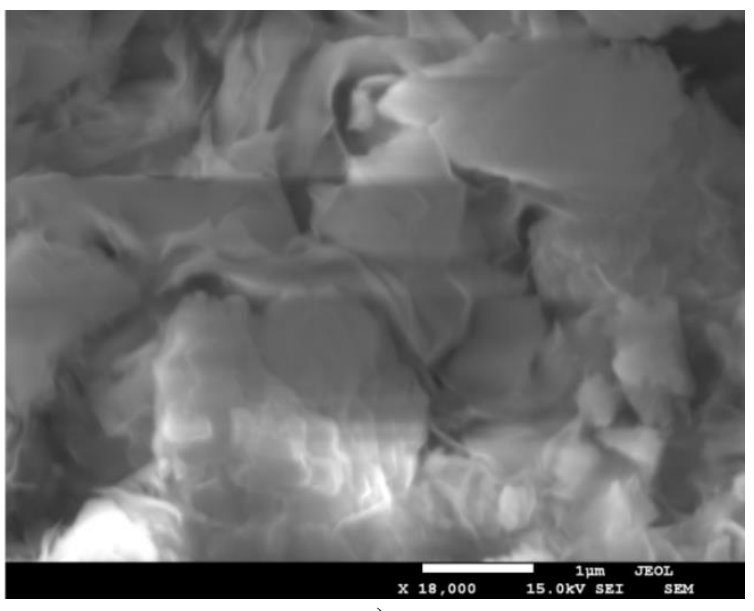

a)

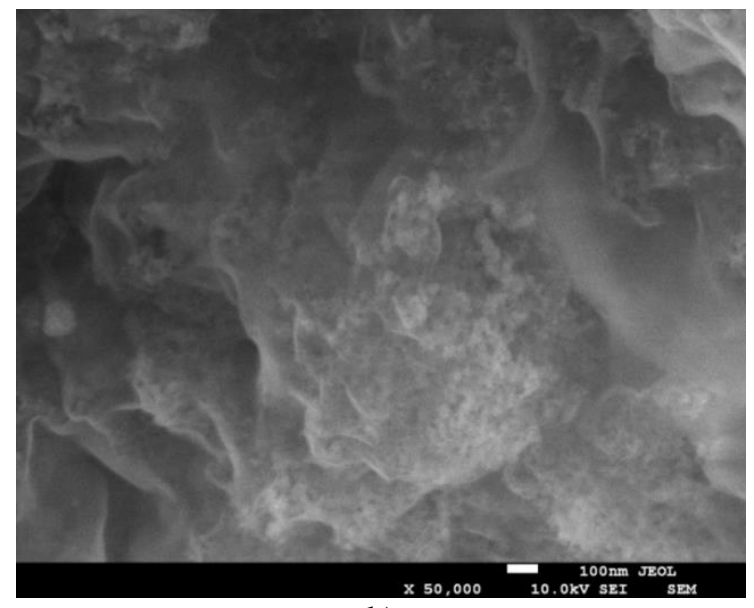

b)

Fig. 5. The SEM image of filter cake without nanoparticles (a); containing $2 \mathrm{wt} \%$ of $\mathrm{SiO}_{2}$ nanoparticles $5 \mathrm{~nm}$ in size (b).

\subsection{The effect of the microparticle concentration}

Fig. 6 shows filtration loss depending on the concentration of AlN microparticles for two different ceramic filters. As can be seen, in both cases the filtration loss of the drilling fluid tends to increase with the concentration rise of microparticles. This is due to the fact that the microparticles are placed between the clay flakes, making the cake more loose and permeable. As the concentration of microparticles increases, so does the thickness of the filtration cake. The addition of $2 \%$ of nanoparticles to the drilling fluid containing microparticles leads to a reduction of the filtration loss. At that, as can be seen from the graphs, the higher the concentration of microparticles is, the more significant the impact of nanoparticles on filtration loss becomes. The addition of nanoparticles leads to the fact that the filtration loss decreases monotonically with the increase of the microparticle concentration. This property of nanoparticles can be very useful for the production of weighted drilling fluid, in which microparticles of barite are added in very high concentrations (up to $60 \%$ ). 


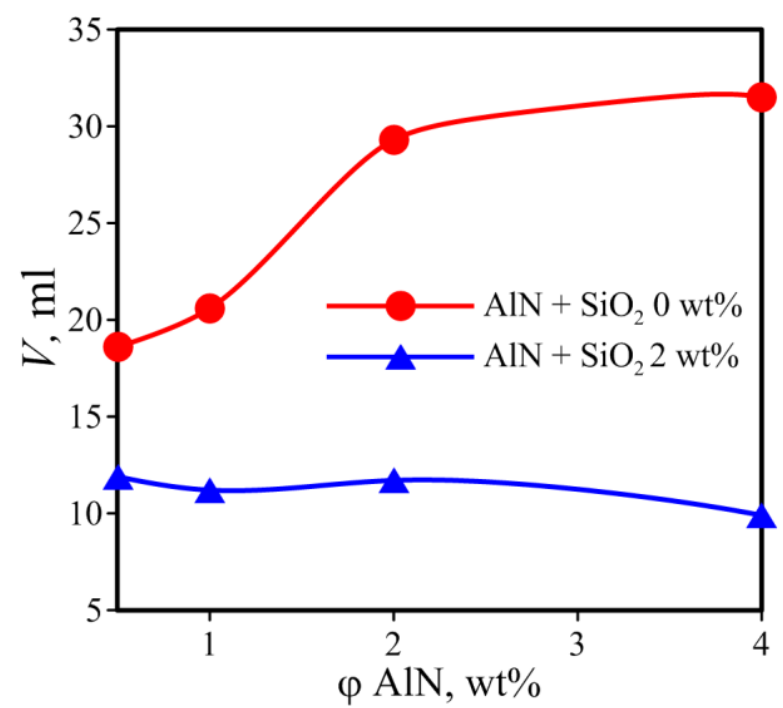

a)

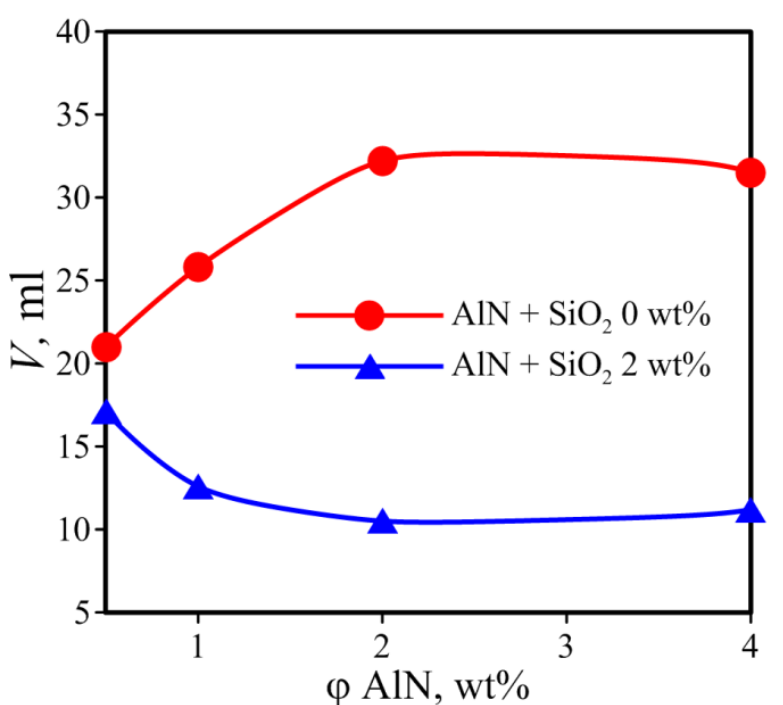

b)

Fig. 6. Filtration loss depending on the concentration of AlN microparticles with a size of $1 \mu \mathrm{m}$ without and with the addition of $2 \mathrm{wt} \%$ of nanoparticles $5 \mathrm{~nm}$ in size for the ceramic filters with pore sizes equal to $3 \mu \mathrm{m}$ (a) and $10 \mu \mathrm{m}$ (b) (by air).

\subsection{The effect of core permeability}

Moreover, the influence of filter permeability on the filtration of drilling fluids with nanoparticles was studied for the first time in the present work. For this purpose, series of measurements were carried out on ceramic filters with pore sizes ranged from 3 to $35 \mu \mathrm{m}$ (by air) and from 10 to $50 \mu \mathrm{m}$ (by mercury). The study was carried out at different concentrations of AlN microparticles with a size of $1 \mu \mathrm{m}$. The nanoparticles of $\mathrm{SiO}_{2}$ with an average size of $5 \mathrm{~nm}$ and a concentration of $2 \mathrm{wt} \%$ were used as additives to the drilling fluid. The results of the experiments are shown in Fig. 7. As the graph shows, filtration loss for both standard and nanoparticle-modified solutions expectedly increases with a larger pore size of the filter. The effect of nanoparticles on the filtration loss of the solution depends on the concentration of microparticles as mentioned above. The analysis of data in Fig. 7 shows that there is an relationship between the concentration of microparticles and the pore size of the filter. As can be seen, the addition of nanoparticles leads to a decrease in filtration loss at a low concentration of microparticles (Fig. 7a) only for filters with pore sizes smaller than $20 \mu \mathrm{m}$ (by air). The addition of nanoparticles leads to a deterioration of filtration loss for filters with the larger pores. As the concentration of microparticles increases, the pore size of the filter at which the addition of 
nanoparticles reduces the filtration loss increases as well. Thus, at a concentration of microparticles of $2 \%$, the addition of $2 \%$ of nanoparticles leads to a decrease in filtration loss for all considered pore sizes (see Fig. 7c). Especially effective nanoparticle addition is manifested for poorly permeable cores with pore sizes less than $10 \mu \mathrm{m}$ (by air). In this case, an almost threefold decrease in the filtration rate compared to the base solution was observed. The conducted analysis has shown that a very dense cake with a thickness of 1-2 $\mathrm{mm}$ is formed on the surface of poorly permeable filters. The efficiency of the added nanoparticles is reduced with the increase in pore size. Thus, for the first time, it was revealed that the effect of nanoparticles on the filtration loss of drilling fluids depends on the ratio of the microparticles concentration and the pore size of the filter. The larger the size of the filter pores is, the higher concentrations of microparticles are at which the addition of the nanoparticles becomes effective. Nanoparticles without microparticles are not able to form a cake on the filter surface. Figure 7 shows that a certain amount of microparticles is necessary for the formation of a cake. When there are enough microparticles and a cake is formed, the nanoparticles fill the area between the microparticles and the cake becomes poorly permeable.

Measurements of the ceramic filters permeability after filtration can also serve the evidence of the fact that the filter cake plays a key role in the filtration of microsuspensions containing nanoparticles (Fig. 8.). These measurements have shown that permeability of cores after filtration through them of microsuspensions with and without the addition of nanoparticles differs slightly. At that, the addition of nanoparticles leads to a significant reduction in the filtration. Thus, it was shown that although the effect of additional colmatating properties of nanoparticles in the porous medium itself takes place, it is insignificant. The main effect of the addition of nanoparticles consists of reducing the permeability of the filter cakes. 


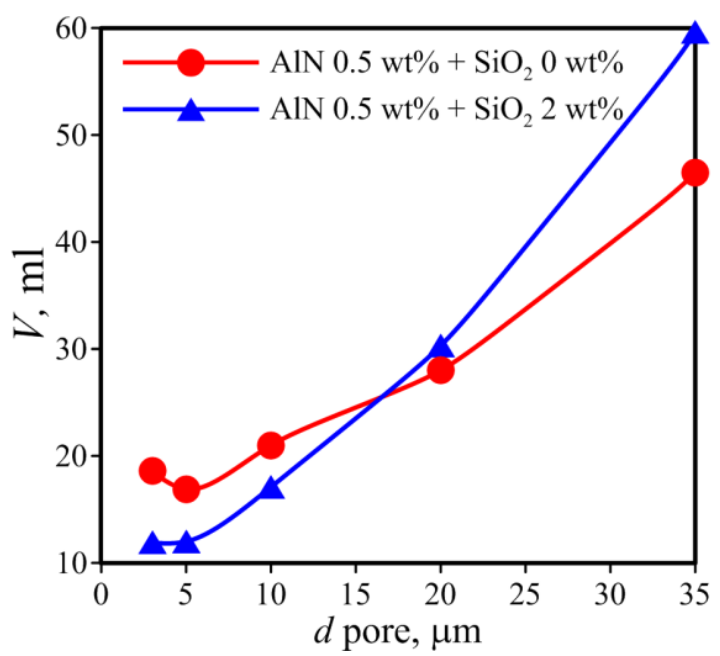

a)

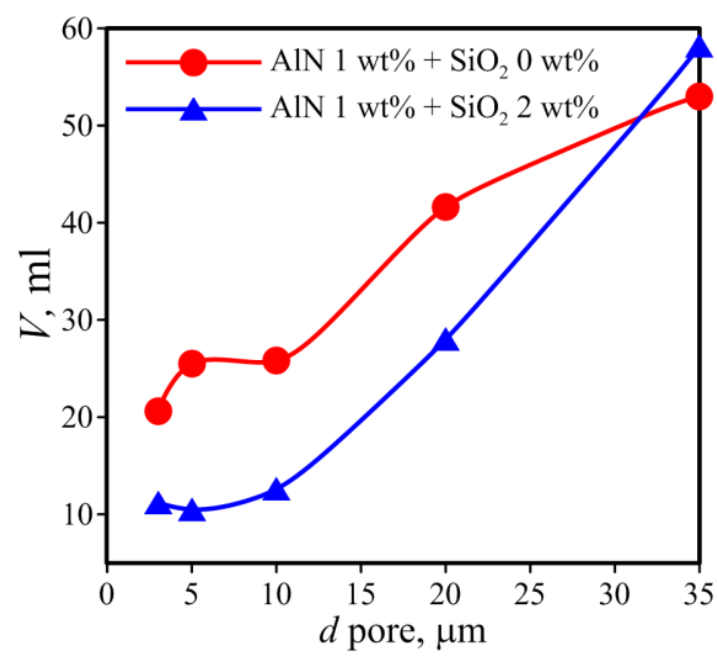

b)

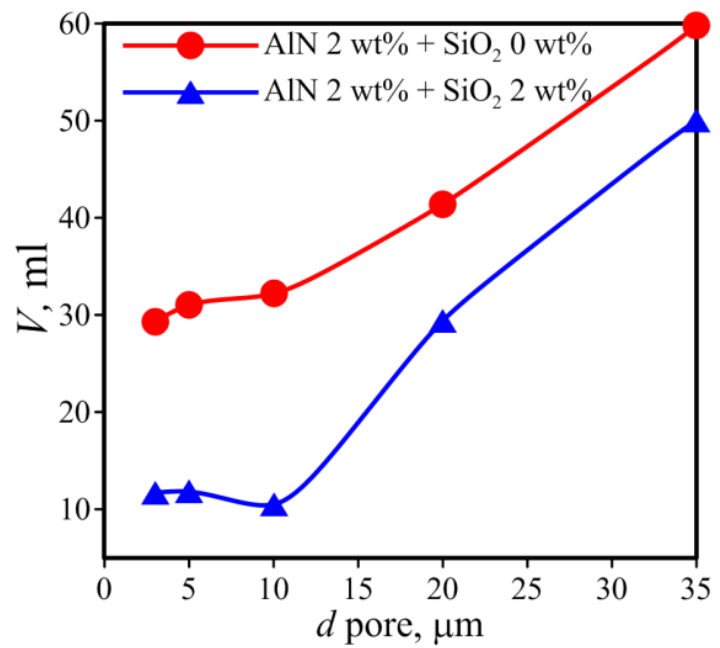

c)

Fig. 7. Filtration loss depending on the pore size of ceramic filters (by air) at concentrations of microparticles with a size of $1 \mu \mathrm{m}$ equal to a) 0.5 , b) 1 and c) $2 \mathrm{wt} \%$ containing $2 \mathrm{wt} \%$ of $\mathrm{SiO}_{2}$ nanoparticles $5 \mathrm{~nm}$ in size.

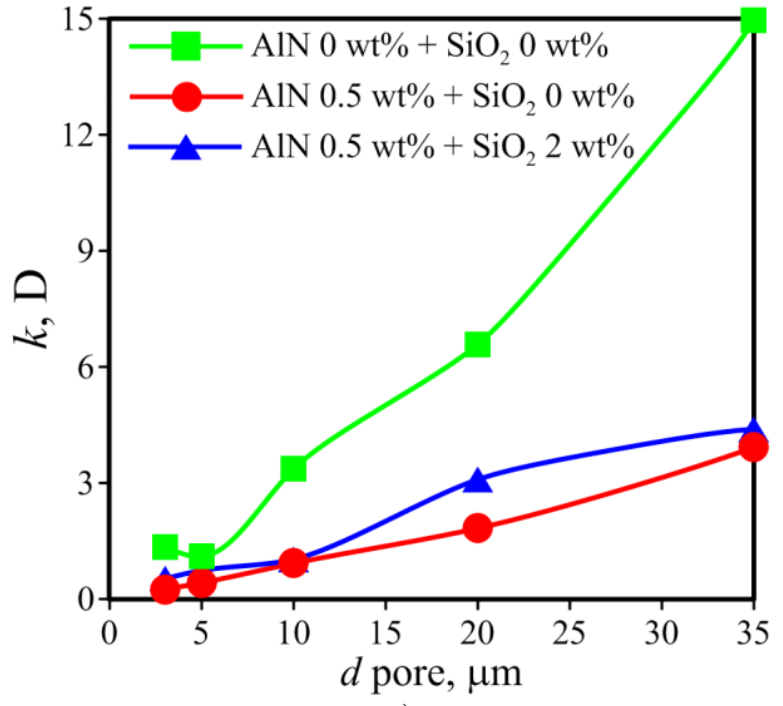

a)

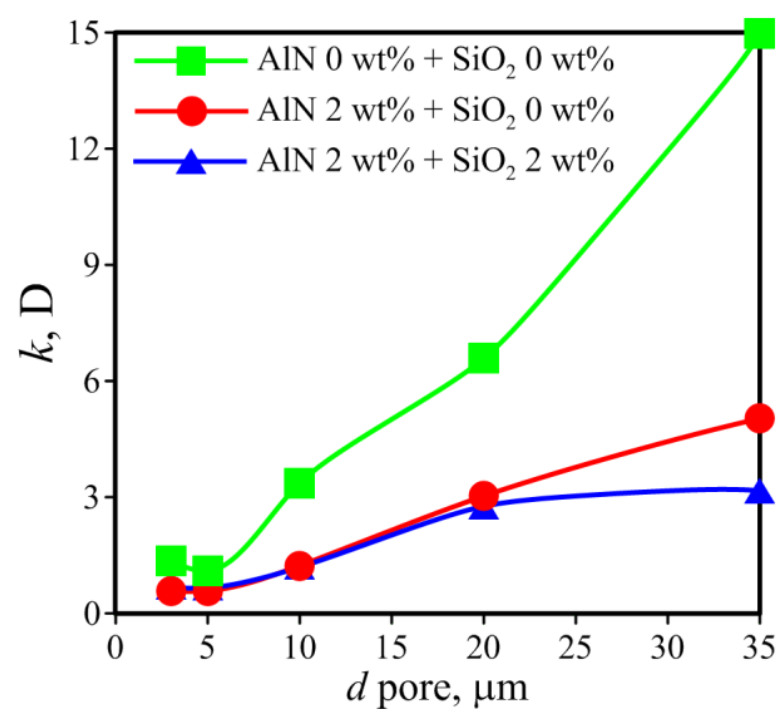

b)

Fig. 8. The permeability of ceramic filters depending on the size of their pores (by air) after filtration through them of microsuspension containing AlN microparticles $1 \mu \mathrm{m}$ in size and $\mathrm{SiO}_{2}$ nanoparticles $5 \mathrm{~nm}$ in size. 


\subsection{The effect of nanoparticle size}

The effect of the nanoparticle size was studied. The dependence of the filtration loss on the average nanoparticle size for a filter with a pore size of $20 \mu \mathrm{m}$ (by air) and at a nanoparticle concentration of $2 \mathrm{wt} \%$ is shown in Fig. 9. It was found that the size of nanoparticles also has a significant effect on the filtration loss of drilling fluid. As the size of nanoparticles decreases, the filtration loss also decreases monotonically. At the same time, it can be observed that particles larger than $50 \mathrm{~nm}$ have almost no noticeable impact on the filtration of microsuspension. Electron microscopy images show that this is due to the fact that nanoparticles cannot penetrate into the pores among the clay particles with such a large size. Analysis of cakes formed on the surface of ceramic filters has shown that at the sizes of nanoparticles smaller than $40 \mathrm{~nm}$ the cakes are thin (2-3 mm) but relatively firm. Cakes are thicker and loose with nanoparticles larger than $50 \mathrm{~nm}$. As the size of nanoparticles decreases, so does the filter cake thickness in general.

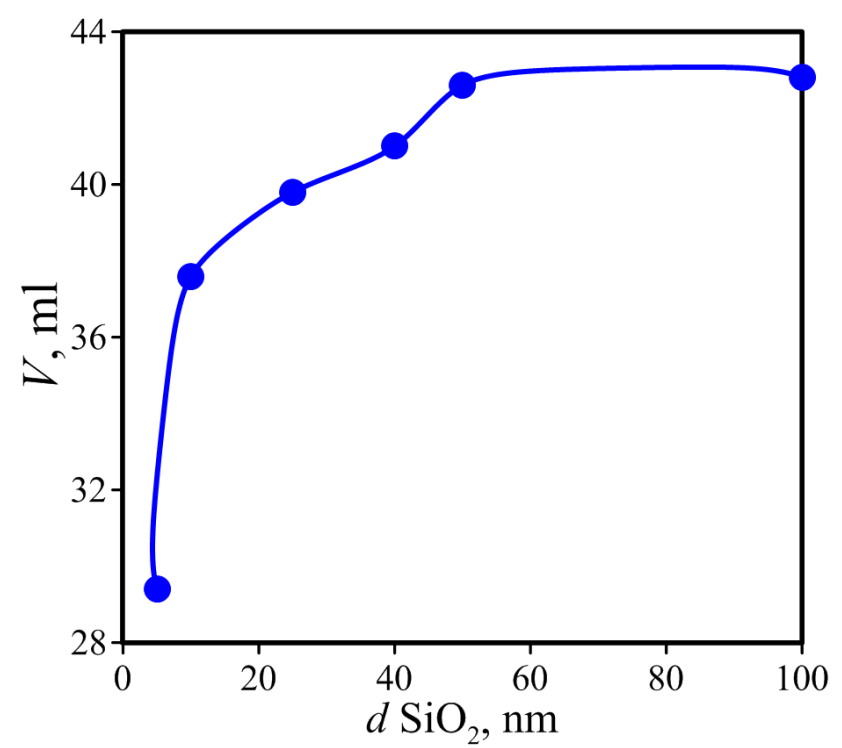

Fig. 9. Filtration loss of microsuspension containing AlN microparticles 1 micron in size at a concentration of 2 wt $\%$ depending on the average size of $\mathrm{SiO}_{2}$ nanoparticles at a concentration of $2 \mathrm{wt} \%$ for a ceramic disk with a pore diameter of $20 \mu \mathrm{m}$ (by air).

\subsection{The effect of the microparticles size}

Further, the effect of the microparticle size on the filtration capacity of drilling fluid with nanoparticles was investigated. At present, the effect of the microcolmatant size on the drilling fluids filtration is well studied (Dick et al., 2000; Abrams, 1977; Kaeuffer, 1973; Vickers et al., 
2006). Data on the mutual influence of the sizes of micro and nanoparticles on the filtration loss of drilling fluids are currently not available. Such a study was carried out in the present work. The concentration of AlN microparticles in these experiments was the same and equal to $2 \mathrm{wt} \%$. The average size of microparticles varied from 1 to $10 \mu \mathrm{m}$. The study was carried out on ceramic discs, whose pore size ranged from 3 to $35 \mu \mathrm{m}$ (by air). It is known that if the colmating mixture consists of particles much larger than the pore opening size, they are not able to form an effective filter cake since the solution is freely filtered through the channels formed between the particles. The particles much smaller than the holes of the pores will freely penetrate into the pore space of the filter. The correct distribution of particles by size in the composition of the colmatant contributes to the formation of a filter cake with minimal penetration of filtrate and solid particles. A typical experimental result of the microsuspension filtration illustrating this behavior is shown in Fig. 10. As can be seen, minimum filtration loss is observed at the size of microparticles of $2 \mu \mathrm{m}$ without the addition of nanoparticles. The addition of $2 \%$ of $\mathrm{SiO}_{2}$ nanoparticles $5 \mathrm{~nm}$ in size leads to a significant reduction of filtration loss for all sizes of microparticles. At that, it is interesting to note that the minimum impact of the nanoparticles is observed for the optimal size of microparticles equal to $2 \mu \mathrm{m}$.

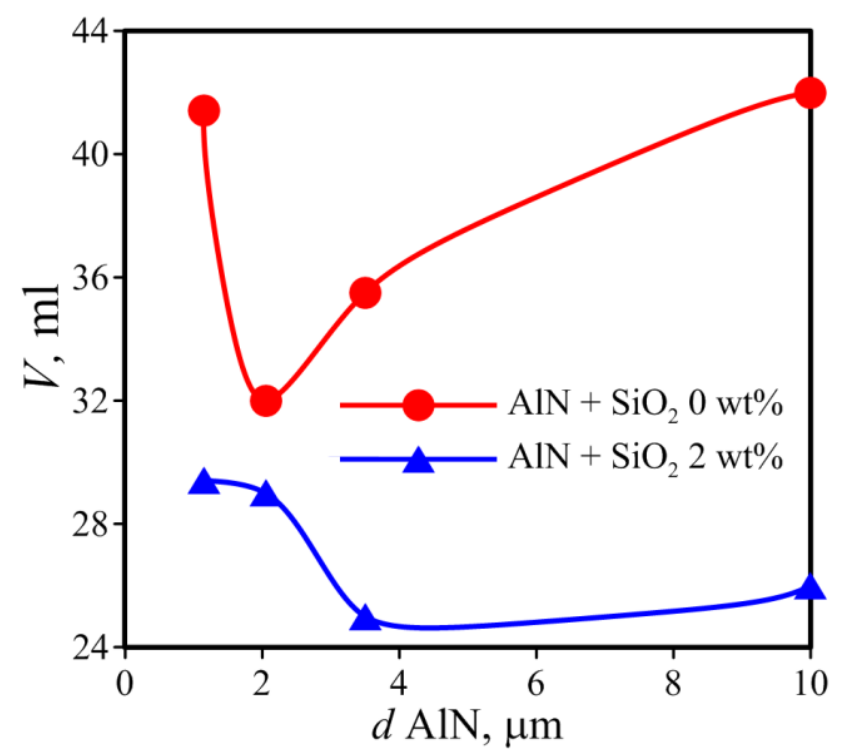

Fig. 10. The filtration loss of drilling fluid depending on the size of microparticles of AlN with 2 wt $\%$ containing 2 $\mathrm{wt} \%$ of $\mathrm{SiO}_{2}$ nanoparticles $5 \mathrm{~nm}$ in size for the ceramic filter with an average pore size of $20 \mu \mathrm{m}$ (by air). 
It is well known that the filtration capacity of drilling fluids with particles is influenced not only by the particle size but by the ratio between the particle and filter pore sizes. According to the Abrams criterion (Abrams, 1977; Vickers et al., 2006), the optimal particle size capable of forming bridges in the filter pore space must be equal to or greater than $1 / 3$ of the average pore size of the filter. Data on the filtration of drilling fluids with microparticles of different sizes through filters with different pore sizes are shown in Fig. 11. At that, the filtration loss is shown depending on the ratio of the average size of microparticles to the average pore size of the filter. As can be seen from the graph, without the addition of nanoparticles, the minimum filtration loss corresponds to the ratio between a particle (PA) and pore (PO) sizes equal to 0.36. This is in good agreement with the Abrams criterion. The addition of the nanoparticles leads to a decrease in filtration loss for all the ratios between particle and pore size. The significant fact is that, when nanoparticles are added to the drilling fluid, filtration loss within a wide range is weakly dependent on the PA/PO ratio on that occasion. Thus, the addition of nanoparticles to the drilling fluid will greatly facilitate the selection of the fractional composition of colmatants, because the addition of nanoparticles reduces the dependence of filtration loss on a ratio of sizes of colmatant particles and core pores.

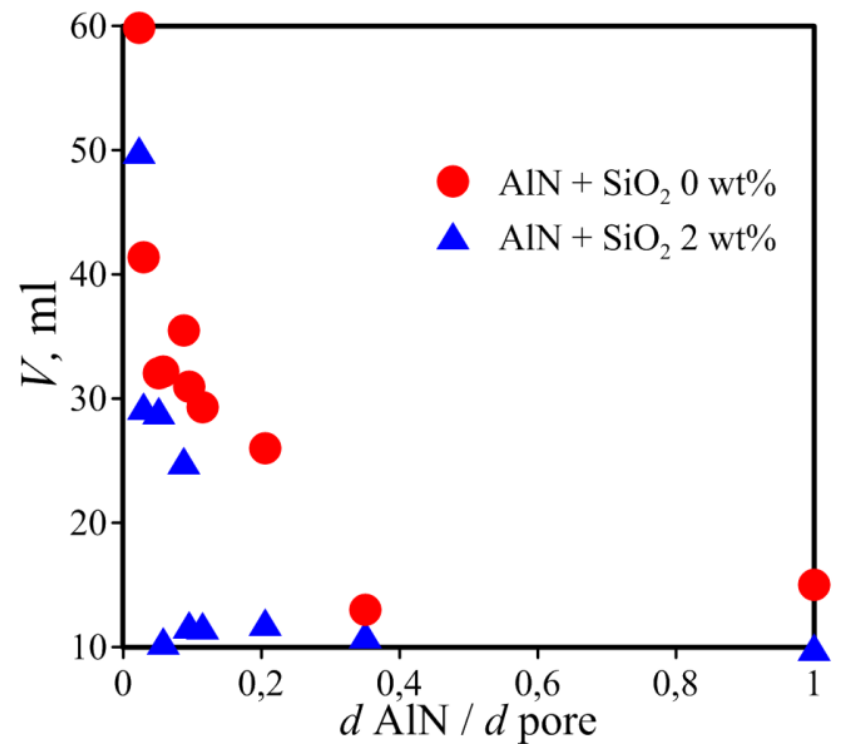

Fig. 11. The filtration loss of drilling fluid containing $\mathrm{SiO}_{2}$ nanoparticles $5 \mathrm{~nm}$ in size at a concentration of $2 \mathrm{wt} \%$ depending on the ratio of the AlN microparticle size at the concentration of $2 \mathrm{wt} \%$ to the average pore size of the filter, defined by the mercury. 


\section{Conclusions}

This paper presents the results of a detailed and systematic study of the effect of nanoparticle additives on the filtration loss of clay drilling fluid with microcolmatants. It is shown that the addition of nanoparticles in the drilling fluid significantly affects the filtration loss even at low concentrations. The influence of the concentration and size of nanoparticles, microparticles, as well as the pore size of ceramic filters on the filtration loss of drilling fluids was studied. The following conclusions were drawn in consequence of conducted research.

1. The dependence of filtration loss on the nanoparticle concentration is non-monotonic in nature. The maximum reduction of filtration loss by 1.7 times is observed for the nanoparticle mass concentration of $1 \%$. A further increase in the concentration of nanoparticles is inexpedient, since it leads to an increase in filtration loss, although insignificant.

2. The size of the nanoparticles also has a significant effect on the filtration loss of the drilling fluid. As the size of nanoparticles decreases, filtration loss also decreases monotonically. It was shown that the addition of nanoparticles larger than $50 \mathrm{~nm}$ has virtually no noticeable effect on the filtration of microsuspension on that occasion.

3. It is shown that the microparticles present in the drilling fluid have a key effect on the filtration of drilling fluids containing nanoparticles. The higher the concentration of microparticles is, the more significant the beneficial effect of nanoparticles on filtration loss is. This property of nanoparticles will be very useful for the production of weighted drilling fluids, in which microparticles are added at very high concentrations.

4. The influence of the filter permeability on the filtration of drilling fluids with nanoparticles was investigated. For the first time, it was revealed that the effect of nanoparticles on the filtration loss of drilling fluids depends on the ratio of the microparticle concentration and the pore size of the filter. The larger filter pores are, the higher the concentration of microparticles at which the positive effect of added nanoparticles becomes noticeable, is. 
5. The effect of the microparticle size on the filtration loss of drilling fluids with nanoparticles was studied. It is investigated that the addition of nanoparticles leads to a decrease in filtration loss regardless of the ratio between the sizes of microparticles and the filter pores. Thus, the addition of nanoparticles to the drilling fluid will allow significantly facilitating the efforts on the selection of the fractional composition of colmatants, since the addition of nanoparticles reduces the dependence of filtration loss on the ratio of the sizes of the colmatant particles and the pores of the core.

6. It is revealed that the addition of nanoparticles affects the structure and thickness of the cake formed on the surface of the filter. It is shown that the thickness of the filtration cake decreases with an increasing concentration of nanoparticles. The addition of nanoparticles to a microsuspension leads to the formation of rather dense and homogeneous cake of 1-3 mm thick. At the same time, the adhesion of the cake to the filter is very high unlike microsuspensions.

7. Scanning electron microscopy was used to study the microstructure and phase composition of cakes after filtration. It was shown that the addition of nanoparticles to the solution with microparticles leads to the fact that nanoparticles fill the pores between the clay flakes and microparticles, thereby reducing the permeability of the cakes on the filter surface.

8. It is shown that permeability of cores after filtration through them of microsuspensions with and without additives of nanoparticles differs slightly. At that, the addition of nanoparticles leads to a significant reduction in the filtration.

9. Analyzing all the obtained facts, it can be argued that the main mechanism of filtration loss reduction of microparticles (clay and microcolmatants) incorporated drilling fluids after adding nanoparticles is associated mainly with a reduction in permeability of the filter cake and caused by the filling of pores between the microparticles with nanoparticles.

Thus, it was shown that filtration of drilling fluids with nanoparticles depends on many interrelated factors, such as concentration, size, and material of nanoparticles, the concentration and size of the microparticles, the pore sizes of ceramic filters, etc. This gives a very broad 
prospect for using nanoparticles to control the properties of drilling fluids. Besides, the above conclusions explain already mentioned differences in the research results of the filtration of drilling fluid with nanoparticles obtained by different authors. The main reason for the distinction in the experiments of different authors is the fact that the effect of the nanoparticles addition on filtration losses depends on the ratio between nano and microparticles, what was shown for the first time in the current article. Previously, such comprehensive studies of the nanoparticle additives effect on the drilling fluid filtration were not carried out. 


\section{Acknowledgements}

The research was performed with the financial support of the Russian Science Foundation under project No. 17-79-20218.

\section{References}

1. Abrams, A., 1977. Mud design to minimize rock impairment due to particle invasion. J. Petrol. Tech. 29 (5), 586-592. https://doi.org/10.2118/5713-PA

2. Akhtarmanesh, S., Shahrabi, M.J.A., Atashnezhad, A., 2013. Improvement of wellbore stability in shale using nanoparticles. J. Petrol. Sci. Eng. 112, 290-295. https://doi.org/10.1016/j.petrol.2013.11.017

3. Contreras, O., Hareland, G., Husein, M., Nygaard, R., Alsaba, M., 2014. Wellbore strengthening in sandstones by means of nanoparticle-based drilling fluids. SPE-170263-MS. https://doi.org/10.2118/170263-MS

4. Dhiman, P., 2016. Experimental investigation of the influence of various nanoparticles on water-based mud. MSci. Thesis, University of Alaska Fairbanks.

5. Dick, M.A., Heinz, T.J., Svoboda, C.F., 2000. Optimizing the selection of bridging particles for reservoir drilling muds. SPE-58793. https://doi.org/10.2118/58793-MS

6. Evdokimov, I.N., 2016. "Nanofluids" and "smart fluids" in oil and gas field development technologies. Nedra Publishing House, Moscow.

7. Hoelscher, K.P., Stefano G., Riley M., Young S., 2012. Application of nanotechnology in drilling muds. SPE. 157031. https://doi.org/10.2118/157031-MS

8. Ismail, A.R., Seong, T.C., Buang, N.A., Sulaiman, W.R.W., 2014a. Improve performance of water-based drilling fluids using nanoparticles. In: Proceedings of the 5th Sriwijaya International Seminar on Energy and Environmental Science \& Technology, Indonesia, pp. 43-47. 
9. Ismail, A.R., Seong, T.C., Buang, N.A., Sulaiman W.R.W., 2014b. Improve the performance of water-based drilling muds using nanoparticles. The 5th Sriwijaya International Seminar on Energy and Environmental Science \& Technology Palembang, Indonesia, pp. 43-47.

10. Jung, Y., Barry, M., Lee, J-K., Tran, P., Soong, Y., Martello, D., Chyu, M., 2011. Effect of nanoparticle-additives on the rheological properties of clay-based fluids at high temperature and high pressure. AADE-11-NTCE-2.

11. Kaeuffer, M., 1973. Determination de l'optimum de remplissage granulometrique et quelques proprietes S'y Rattachant. Congres de I'AFTPV, Rouen.

12. Kang, Y., She, J., Zhang, H., You, L., Song, M., 2016. Strengthening shale wellbore with silica nanoparticles drilling fluid. Petroleum. 2 (2), 189-195. https://doi.org/10.1016/j.petlm.2016.03.005

13. Li, M-C., Wu, Q., Song, K., Qing, Y., Wu, Y. 2105a. Cellulose nanoparticles as modifiers for rheology and fluid loss in bentonite water-based fluids. ACS Appl. Mater. Interfaces. 7-8, 5006-5016. https://pubs.acs.org/doi/10.1021/acsami.5b00498

14. Li, M., Wu, Q., Song, K., Hoop, K.F., Lee, S-Y., Qing, Y., Wu, Y., 2015b. Cellulose nanocrystals and polyanionic cellulose as additives in bentonite water-based drilling muds: rheological modelling and filtration mechanisms. Ind Eng Chem Res. 55, 133-143. https://pubs.acs.org/doi/10.1021/acs.iecr.5b03510

15. Mahmoud, O., Nasr-El-Din, H.A., Vryzas, Z., Kelessidis, V.C., 2016 Nanoparticlebased drilling muds for minimizing formation damage in HP/HT applications. SPE178949-MS. https://doi.org/10.2118/178949-MS

16. Mijić, P., Gaurina-Međimurec, N., Pašić, B., 2017. The influence of $\mathrm{SiO}_{2}$ and $\mathrm{TiO}_{2}$ nanoparticles on the properties of water-based mud. ASME 36th International Conference on Ocean, Offshore and Arctic Engineering. V008T11A002. https://doi.org/10.1115/OMAE201761276 
17. Minakov, A.V, Mikhienkova, E.I., Neverov, A.L., Buryukin, F.A., 2018a. An experimental study of the effect of nanoparticle additives on the rheological properties of a suspension. Tech. Phys. Lett. 44 (5), 367-370. https://doi.org/10.1134/S1063785018050097

18. Minakov, A.V, Mikhienkova, E.I., Zhigarev, V.A., Neverov, A.L., Rudyak, V. Ya., 2018b. A study of the influence of nanoparticles on the properties of drilling muds. Colloid Journal. 80 (4), 418-426. https://doi.org/10.1134/S1061933X18040099

19. Minakov, A.V, Mikhienkova, E.I., Zhigarev, V.A., Neverov, A.L., 2018c. An experimental study of the influence of added nanoparticles on the filtration of microsuspensions via porous media. Tech. Phys. Lett. 44 (6), 532-534. https://doi.org/10.1134/ S1063785018060251

20. Ragab, A.M.S., Noah A., 2014. Reduction of formation damage and fluid loss using nano-sized silica drilling fluids. Pet. Technol. Dev. J. 2, 75-88.

21. Riveland, F.A., 2013. Investigation of nanoparticles for enhanced filtration properties of drilling mud. MsSci. Thesis. Norwegian University of Science and Technology.

22. Rudyak, V.Ya., Minakov, A.V., Smetanina, M.S., Pryazhnikov, M.I., 2016. Experimental data on the dependence of the viscosity of water-and ethylene glycol-based nanofluids on the size and material of particles. Doklady Physics. 61 (3), 152. https://doi.org/10.1134/S1028335816030113

23. Rudyak, V.Ya., Minakov, A.V., Pryazhnikov, M.I., 2017. Thermal properties of nanofluids and their similarity criteria. Tech. Phys. Lett. 43 (1), 23-26. https://doi.org/10.1134/S106378501612021X

24. Salih, A.H., Elshehabi T.A., Bilgesu H.I., 2016. Impact of nanomaterials on the rheological and filtration properties of water-based drilling muds. SPE-184067-MS. https://doi.org/10.2118/184067-MS

25. Sharma, M.M., Zhang, R., Chenevert, M.E., Ji, L., Guo, Q., Friedheim, J., 2012. A new family of nanoparticle-based drilling fluids. SPE. 160045. https://doi.org/10.2118/160045-MS 
26. Taraghikhah, S., Mohammadi, M.K., Nowtaraki, K.T., 2015. Multifunctional nanoadditive in water-based drilling mud for improving shale stability. IPTC-18323-MS. https://doi.org/10.2523/IPTC-18323-MS

27. Vickers, S., Cowie, M., Jones, T., 2006. A new methodology that surpasses current bridging theories to efficiently seal a varied pore throat distribution as found in natural reservoir formations. Wiertnictwo Nafta Gas. 23 (1), 501-515.

28. Vryzas, Z., Mahmoud O., Nasr-El-Din H.A., Kelessidis V.C., 2015. Development and testing of novel fluids using $\mathrm{Fe}_{2} \mathrm{O}_{3}$ and $\mathrm{SiO}_{2}$ nanoparticles for enhanced drilling operations. IPTC-SPE-178949-MS-MS. https://doi.org/10.2523/IPTC-18381-MS

29. Vryzas, Z., Mahmoud, O., Nasr-El-Din, H.A., Zaspalis, V., Kelessidis, V.C., 2016. Incorporation of $\mathrm{Fe}_{3} \mathrm{O}_{4}$ nanoparticles as drilling mud additives for improved drilling operations. OMAE2016-54071. https://doi.org/10.1115/OMAE2016-54071 